\title{
STABILITY ANALYSIS OF STEEL FRAMES WITH SEMI-RIGID CONNECTIONS AND RIGID ZONES BY USING P-DELTA EFFECT
}

\author{
VU Quoc ANH \\ Faculty of Civil Engineering - Hanoi Architectural University
}

\begin{abstract}
Comparing with reinforced concrete structure, member rigidity of steel structure is less, and displacement of steel structure is larger than that of reinforced concrete structure, so the secondary moment due to axial force has to be considered, i e., the problem of P-Delta effect. For most building structures, especially tall steel buildings, the P-Delta effect of most concern occurs in the columns due to gravity load, including dead and live load. The column axial forces are compressive, making the structure more flexible against lateral loads. If compressive P-forces are present and are large enough, the structure may buckle. Local buckling of individual members or global buckling of the whole structure is possible. This paper presents the method to analysis stability of steel frames with semi-rigid connections and rigid zones by using P-Delta effect.
\end{abstract}

\section{Introduction}

All joints are neither rigid nor pinned, but contain a certain degree of flexibility or rigidity that has a significant influence over the buckling capacity of a steel frame. The adoption of the limit state design concept and optimum design has resulted in the use of slender members in steel framed structures. To predict the load-carrying capacity and the buckling behavior of these structures, rigorous second order nonlinear analysis must be adopted. In an accurate analysis, both the geometric nonlinearity and the joint flexibility play an important role to the stability of steel framed structures. Since they are inter - related and simultaneously affect each other, therefore the stability analysis of steel framed structures can be considered in to nonlinear geometric approach.

The P-Delta effect refers specifically to nonlinear geometric effect of a large tensile or compressive direct stress upon transverse bending and shear behavior. A compressive stress tends to make a structural member more flexible in transverse bending and shear, whereas a tensile stress tends to stiffen the member against transverse deformation. If the compressive force is large enough, the transverse stiffness goes to zero and hence the deflection tends to infinity; the structure is said to have buckled. The theoretical value of $P$ at which this occurs is called the Euler buckling load. P-Delta analysis does not provide a direct method of determining the buckling load of structure. It may be estimated, however, by performing a series of runs, each time increasing the magnitude of the P-Delta load, until buckling is 
detected. It is important to keep unchange the relative contributions from each load case to the P-Delta load, increasing all load case scale factors by the same amount between runs.

It is important to understand that there is no single buckling load for a structure. Rather, there is a different buckling load corresponding to each spacial distribution of loads. If buckling of the structure is a concern under various loading situations, the buckling load should be estimated separately for each situation.

2. To establish the geometric stiffness matrix and stiffness matrix $\left[k_{\sigma}\right]$ and $[k]$ for beam element

Imagine that initial stresses $\left\{\sigma_{0}\right\}$ prevail. If these stresses are assumed to remain constant as strains $\{\varepsilon\}$ occur, the deformation energy is done by second order effect can be written as [1]:

$$
U_{\sigma}=\frac{1}{2} \int_{V e}\left\{u^{\prime}\right\}^{T}\left[\begin{array}{lll}
s & 0 & 0 \\
0 & s & 0 \\
0 & 0 & s
\end{array}\right]\left\{u^{\prime}\right\} d V
$$

where

$$
[s]=\left[\begin{array}{ccc}
\sigma_{x 0} & \tau_{x y 0} & \tau_{z x 0} \\
\tau_{x y 0} & \sigma_{y 0} & \tau_{y z 0} \\
\tau_{z x 0} & \tau_{y z 0} & \sigma_{z 0}
\end{array}\right] .
$$

Let the element displacement field be given by $\{u\}=[N]\{x\}$, as usual, where $\{u\}=\left[\begin{array}{lll}u & v & w\end{array}\right]^{T}$ and $\{x\}$ contains nodal d.o.f. Also let $\left\{u^{\prime}\right\}=[G]\{x\}$, where $[G]$ is obtained from shape functions $[N]$ by appropriate differentiation and ordering of terms. Equation (2.1) becomes

$$
U_{\sigma}=\{x\}^{T}\left[k_{\sigma}\right]\{x\} / 2, \quad \text { where }\left[k_{\sigma}\right]=\int_{V e}[G]^{T}\left[\begin{array}{ccc}
s & 0 & 0 \\
0 & s & 0 \\
0 & 0 & s
\end{array}\right][G] d V .
$$

Then

$$
\delta U_{\sigma}=\int_{V e}\left\{\delta u^{\prime}\right\}^{T}[S]\left\{u^{\prime}\right\} d V=\int_{V e}\{\delta x\}^{T}[G]^{T}[S][G]\{x\} d V=\{\delta x\}^{T}\left[k_{\sigma}\right]\{x\},
$$

where

$$
[S]=\left[\begin{array}{lll}
s & 0 & 0 \\
0 & s & 0 \\
0 & 0 & s
\end{array}\right]
$$


For the conditions of stable equilibrium, i.e., where the axial load is of a value less than critical value, we have the equation as

$$
\int_{V e}\{\delta \varepsilon\}^{T}[E]\{\varepsilon\} d V+\int_{V e}\left\{\delta u^{\prime}\right\}^{T}[S]\left\{u^{\prime}\right\} d V=\int_{V e}\{\delta u\}^{T}\{q\} d V,
$$

where $\{\delta u\}$ and $\{\delta \varepsilon\}$ are respectively small arbitrary displacements and their corresponding strains, $[E]$ is the material property matrix, $\{q\}$ are body forces, and volume integration is carried out over the element volume $V e$

$$
\{\delta x\}^{T}\left[\int_{V e}[B]^{T}[E][B]\{x\} d V+\int_{V e}[G]^{T}[S][G]\{x\} d V\right]=\{\delta x\}^{T}\left[\int_{V e}[N]^{T}\{q\} d V\right] .
$$

Denote $\left[k_{\sigma}\right]=\int_{V e}[G]^{T}[S][G] d V$ the geometric stiffness matrix; $[k]=\int_{V e}[B]^{T}[E][B] d V$ the stiffness matrix and $\{f\}=\int_{V e}[N]^{T}\{q\} d V$ the vector of nodal point forces of beam element, since $\{\delta x\}$ is arbitrary, $\mathrm{Eq}(2.6)$ can be written as [1]

$$
[k]\{x\}+\left[k_{\sigma}\right]\{x\}=\left([k]+\left[k_{\sigma}\right]\right)\{x\}=\{f\} .
$$

As an example, consider the beam of Fig. 1a, with motion restricted to $x z$ plane. For this case, all initial stresses are zero except for axial stresses $\sigma_{x 0}$. Four d.o.f define a cubic lateral displacement field. Accordingly, with

$N_{1}=1-\frac{3 x^{2}}{L^{2}}+\frac{2 x^{3}}{L^{3}} ; \quad N_{2}=x-\frac{2 x^{2}}{L}+\frac{x^{3}}{L^{2}} ; \quad N_{3}=\frac{3 x^{2}}{L^{2}}-\frac{2 x^{3}}{L^{3}} ; \quad N_{4}=-\frac{x^{2}}{L}+\frac{x^{3}}{L^{2}}$, we write

$$
\begin{aligned}
w & =N_{1} x_{1}+N_{2} x_{2}+N_{3} x_{3}+N_{4} x_{4} ; \quad u=0 ; \quad v=0 \\
{[G] } & =\left[\begin{array}{llll}
-\frac{6 x}{L^{2}}+\frac{6 x^{2}}{L^{3}} & 1-\frac{4 x}{L}+\frac{3 x^{2}}{L^{2}} & \frac{6 x}{L^{2}}-\frac{6 x^{2}}{L^{3}} & -\frac{2 x}{L}+\frac{3 x^{2}}{L^{2}}
\end{array}\right], \\
{[S] } & =\left[\sigma_{x 0}\right] .
\end{aligned}
$$

Nonzero d.o.f are $\{x\}=\left[\begin{array}{llll}x_{1} & x_{2} & x_{3} & x_{4}\end{array}\right]^{T}$ and $\left\{u^{\prime}\right\}=\left[w_{x}^{\prime}\right]^{T}$.

The geometric stiffness matrix of beam element (2.3) reduces to

$$
\left[k_{\sigma}\right]=\int_{0}^{\ell}[G]^{T}\left[\sigma_{x 0}\right][G] A d x=\frac{P}{30 L}\left[\begin{array}{cccc}
36 & 3 L & -36 & 3 L \\
3 L & 4 L^{2} & -3 L & -L^{2} \\
-36 & -3 L & 36 & -3 L \\
3 L & -L^{2} & -3 L & 4 L^{2}
\end{array}\right]
$$


where $P=\sigma_{x 0} A$.

The stiffness matrix of beam element is created as [1]

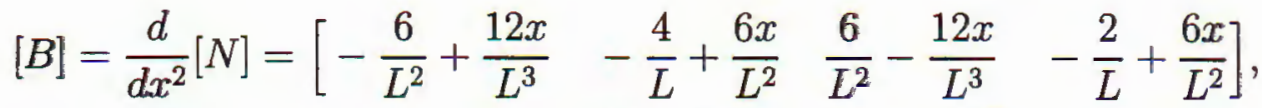

$$
\begin{aligned}
& {[k]=\int_{0}^{L}[B]^{T} E J[B] d x=\frac{E J}{L^{3}}\left[\begin{array}{cccc}
12 & 6 L & -12 & 6 L \\
6 L & 4 L^{2} & -6 L & 2 L^{2} \\
-12 & -6 L & 12 & -6 L \\
6 L & 2 L^{2} & -6 L & 4 L^{2}
\end{array}\right] .}
\end{aligned}
$$

3. To establish the geometric stiffness matrix $\left[k_{\sigma}^{*}\right]$ and stiffness matrix $\left[k^{*}\right]$ for beam element with semi-rigid connections and rigid zones

To incorporate the connection rigidity into the member stiffness, it is a common practice to model the semi-rigid connection as massless and zero length rotational spring. Although semi-rigid connections exhibit nonlinear response characteristics throughout their whole loading history, it is generally accepted that under service loading conditions the semi-rigid connections can be assumed to behave linearly.

For a single element with semi-rigid connections and rigid-zones, the work balance with consideration of P-delta effect becomes

$$
\int_{V e}\{\delta \varepsilon\}^{T}[E]\{\varepsilon\} d V+\left\{\delta u_{k}\right\}^{T}\left[k_{k}\right]\left\{u_{k}\right\}+\int_{V e}\left\{\delta u^{\prime}\right\}[S]\left\{u^{\prime}\right\} d V=\int_{V e}\{\delta u\}^{T}\{q\} d V,
$$

where $\{\delta u\}$ and $\{\delta \varepsilon\}$ are respectively small arbitrary displacements and their corresponding strains, $[E]$ is the material property matrix, $\left[k_{k}\right]$ is the stiffness matrix of the springs, $\left\{\delta u_{k}\right\}^{T}$ are the small displacement of the springs, $\{q\}$ are body forces, and volume integration is carried out over the element volume $V e$.

Using usual notation, we have for displacement field $\{u\}$ (which is a function of both space and time)

$$
\begin{gathered}
\{u\}=[N]\{x\} ; \quad\{x\}=[T]\{X\} ; \quad\{X\}=[e]\left\{X^{*}\right\} \\
\{u\}=[N][T][E]\left\{X^{*}\right\} ;\left\{u^{\prime}\right\}=[G]\{x\}=[G][T][e]\left\{X^{*}\right\},\left\{u_{k}\right\}=\left[x_{1}^{k} x_{2}^{k} x_{3}^{k} x_{4}^{k}\right]^{T} \\
\left\{u_{k}\right\}=\{X\}-\{x\}=\{X\}-[T]\{X\}=[1-T]\{X\}=[1-T][e]\left\{X^{*}\right\} ; \quad e=[B]\{x\} \\
\left\{\delta u_{k}\right\}^{T}\left[k_{k}\right]\left\{u_{k}\right\}=\delta x_{2}^{k} k_{1} x^{2}+\delta x_{4}^{k} k_{2} x_{4}^{k}=\left[\delta x_{1}^{k} \delta x_{2}^{k} \delta x_{3}^{k} \delta x_{4}^{k}\right]\left[\begin{array}{cccc}
0 & 0 & 0 & 0 \\
0 & k_{1} & 0 & 0 \\
0 & 0 & 0 & 0 \\
0 & 0 & 0 & k_{2}
\end{array}\right]\left[\begin{array}{c}
x_{1}^{k} \\
x_{2}^{k} \\
x_{3}^{k} \\
x_{4}^{k}
\end{array}\right] \\
\left\{u_{k}\right\}=\{X\}-\{x\}=\{X\}-[T]\{X\}=[1-T]\{X\}=[1-T][e]\left\{X^{*}\right\}
\end{gathered}
$$


In Eqs. (3.2), shape functions $[N]$ are functions of space, $[T]$ and $[e]$ are transformation matrices. Thus Eqs. (3.2) represent a local separation of variables. Combination of Eqs. (3.1) and (3.2) yields

$$
\begin{aligned}
& \left\{\delta X^{*}\right\}^{T}\left[\int_{V e}[e]^{T}[T]^{T}[B]^{T}[E][B][T][e]\left\{X^{*}\right\} d V+[e]^{T}[1-T]^{T}\left[k_{k}\right][1-T][e]\left\{X^{*}\right\}+\right. \\
& \left.\int_{V e}[e]^{T}[T]^{T}[G]^{T}[S][G][T][e]\left\{X^{*}\right\} d V\right]=\left\{\delta X^{*}\right\}^{T}\left[\int_{V e}[e]^{T}[T]^{T}[N]^{T}\{q\} d V\right] .
\end{aligned}
$$

Since $\left\{\delta X^{*}\right\}$ is arbitrary, Eq (3.3) can be written as

$$
\left[k^{*}\right]\left\{X^{*}\right\}+\left[k_{\sigma}^{*}\right]\left\{X^{*}\right\}=\left(\left[k^{*}\right]+\left[k_{\sigma}^{*}\right]\right)\left\{X^{*}\right\}=\left\{F^{*}\right\},
$$

where $\left[k^{*}\right],\left[k_{\sigma}^{*}\right]$ are the stiffness matrix, geometric stiffness matrix of the element with semi-rigid connections and rigid-zones; $\left\{F^{*}\right\}$ are external load vectors; $\left\{X^{*}\right\}$ is the displacement vector of the element with semi-rigid connections and rigid-zones.

They are defined as:

$$
\begin{aligned}
{\left[k^{*}\right] } & \left.=\int_{V e}[e]^{T}[T]^{T}[B]^{T}[E][B][T][e] d V+[e]^{T}[1-T]^{T}\right]\left[k_{k}\right][1-T][e] \\
& =[e]^{T}[T]^{T}\left[\int_{V e}[B]^{T}[E][B] d V\right][T][E]+[e]^{T}[1-T]^{T}\left[k_{k}\right][1-T][e] \\
& =[e]^{T}\left([T]^{T}[k][T]+[1-T]^{T}\left[k_{k}\right][1-T]\right)[e]=[e]^{T}[k][T][e], \\
{\left[k_{\sigma}^{*}\right]=} & \int_{V e}[e]^{T}[T]^{T}[G]^{T}[S][G][T][e] d V=[e]^{T}[T]^{T}\left[\int_{V e}[G]^{T}[S][G] d V\right][T][e] \\
= & {[e]^{T}[T]^{T}\left[k_{\sigma}\right][T][e], } \\
\left\{F^{*}\right\}= & {[e]^{T}[T]^{T}\{f\}, \quad \text { where }[5] \quad\{f\}=\int_{V e}[N]^{T}\{q\} d V . }
\end{aligned}
$$

4. To establish the transformation matrixes $[T]$ and $[e]$

The well-known elastic force displacement relationship [2], Fig. 1a, for prismatic beam without shearing deformation, is: '

$$
\left[\begin{array}{l}
f_{1} \\
f_{2} \\
f_{3} \\
f_{4}
\end{array}\right]=\frac{E J}{L^{3}}\left[\begin{array}{cccc}
12 & 6 L & -12 & 6 L \\
6 L & 4 L^{2} & -6 L & 2 L^{2} \\
-12 & -6 L & 12 & -6 L \\
6 L & 2 L^{2} & -6 L & 4 L:^{2}
\end{array}\right]\left[\begin{array}{l}
x_{1} \\
x_{2} \\
x_{3} \\
x_{4}
\end{array}\right] \quad \text { or, }\{f\}=[k]\{x\} .
$$


Structural model of beam with semi-rigid connections is shown in Fig. 1 and beam with semi-rigid connections and rigid-zones in Fig. 2,
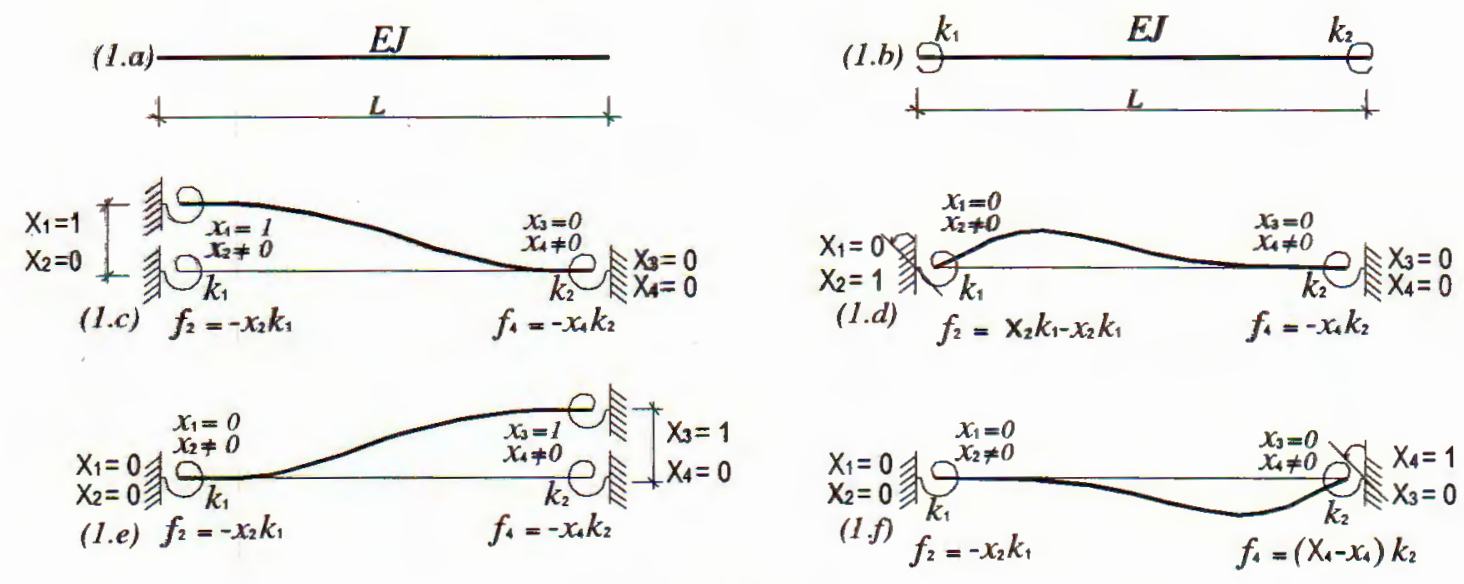

Fig. 1
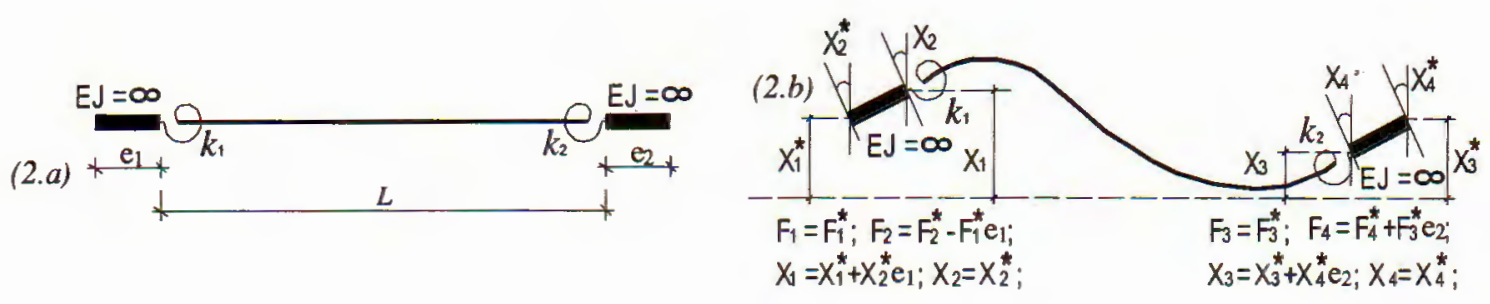

Fig. 2

where: $\left[k_{e s}\right]$ - stiffness matrix of beam with semi-rigid connections; $\{X\}$ - vector of nodal point displacements of beam with semi-rigid connections; $\{F\}$ - vector of nodal point forces of beam with semi-rigid connections; $e_{1}, e_{2}$ - length of rigid-zones (rigid offset) of connections; $\{X *\}$ - vector of nodal point displacements of beam with semi-rigid connections and rigid-zones; $\left\{F^{*}\right\}$ - vector of nodal point forces of beam with semi-rigid connections and rigid-zones; $k_{1} ; k_{2}$-spring rotation factors of connections.

The elastic force deformation relationship, Fig. 1b, for a prismatic beam with semi-rigid connections, is:

$$
\left[\begin{array}{l}
F_{1} \\
F_{2} \\
F_{3} \\
F_{4}
\end{array}\right]=\left[\begin{array}{llll}
k_{11} & k_{12} & k_{13} & k_{14} \\
k_{21} & k_{22} & k_{23} & k_{24} \\
k_{31} & k_{32} & k_{33} & k_{34} \\
k_{41} & k_{42} & k_{43} & k_{44}
\end{array}\right]\left[\begin{array}{l}
X_{1} \\
X_{2} \\
X_{3} \\
X_{4}
\end{array}\right] \quad \text { or, } \quad\{F\}=\left[k_{e s}\right]\{X\} .
$$

The equilibrıum equations of nodal point forces are of the form

$$
\{F\}=\{f\} ; \quad\{F\}=\left[\begin{array}{llll}
F_{1} & F_{2} & F_{3} & F_{4}
\end{array}\right]^{T} ; \quad\{f\}=\left[\begin{array}{llll}
f_{1} & f_{2} & f_{3} & f_{4}
\end{array}\right]^{T} .
$$


The first column of the matrix is created as boundary conditions, Fig. 1c:

$$
\begin{aligned}
& \{X\}=\left[\begin{array}{llll}
X_{1} & X_{2} & X_{3} & X_{4}
\end{array}\right]^{T}=\left[\begin{array}{lll}
1 & 0 & 0
\end{array}\right]^{T}, \\
& f_{2}=-k_{1} x_{2} ; \quad f_{4}=-k_{2} x_{4} ; \quad x_{1}=1, \quad x_{3}=0 .
\end{aligned}
$$

To impose the boundary conditions into equations (4.1) that becomes

$$
\left\{\begin{array} { l } 
{ \frac { 6 E J } { L ^ { 2 } } x _ { 1 } + \frac { 4 E J } { L } x _ { 2 } + \frac { 2 E J } { L } x _ { 4 } = - k _ { 1 } x _ { 2 } } \\
{ \frac { 6 E J } { L ^ { 2 } } x _ { 1 } + \frac { 2 E J } { L } x _ { 2 } + \frac { 4 E J } { L } x _ { 4 } = - k _ { 2 } x _ { 4 } }
\end{array} \Leftrightarrow \left\{\begin{array}{l}
\left(\frac{4 E J}{L}+k_{1}\right) x_{2}+\frac{2 E J}{L} x_{4}=-\frac{6 E J}{L^{2}} \\
\frac{2 E J}{L} x_{2}+\left(\frac{4 E J}{L}+k_{2}\right) x_{4}=-\frac{6 E J}{L^{2}}
\end{array}\right.\right.
$$

Solving equations (4.3) to find $x_{2} ; x_{4}$ :

$$
\begin{aligned}
& x_{2}=\frac{-6 E J\left(2 E J+k_{2} L\right)}{\left(12 E^{2} J^{2}+4 E J k_{2} L+4 L k_{1} E J+L^{2} k_{1} k_{2}\right) L}, \\
& x_{4}=\frac{-6 E J\left(2 E J+k_{1} L\right)}{\left(12 E^{2} J^{2}+4 e J k_{2} L+4 L k_{1} E J+L^{2} k_{1} k_{2}\right) L}, \\
& {\left[\begin{array}{llll}
t_{11} & t_{21} & t_{31} & t_{41}
\end{array}\right]^{T}=\left[\begin{array}{llll}
x_{1} & x_{2} & x_{3} & x_{4}
\end{array}\right]^{T} \text {. }}
\end{aligned}
$$

The second column of the matrix $T$ is created as boundary conditions, Fig. 1d:

$$
\begin{aligned}
& \{X\}=\left[\begin{array}{llll}
X_{1} & X_{2} & X_{3} & X_{4}
\end{array}\right]^{T}=\left[\begin{array}{llll}
0 & 1 & 0 & 0
\end{array}\right]^{T}, \\
& f_{2}=k_{1}-k_{1} x_{2} ; \quad f_{4}=-k_{2} x_{4} ; \quad x_{1}=0, \quad x_{3}=0 .
\end{aligned}
$$

To impose the boundary conditions into equations (4.1) that becomes:

$$
\left\{\begin{array} { l } 
{ \frac { 4 E J } { L } x _ { 2 } + \frac { 2 E J } { L } x _ { 4 } = k _ { 1 } - k _ { 1 } x _ { 2 } } \\
{ \frac { 2 E J } { L } x _ { 2 } + \frac { 4 E J } { L } x _ { 4 } = - k _ { 2 } x _ { 4 } }
\end{array} \Leftrightarrow \left\{\begin{array}{l}
\left(\frac{4 E J}{L}+k_{1}\right) x_{2}+\frac{2 E J}{L} x_{4}=k_{1} \\
\frac{2 E J}{L} x_{2}+\left(\frac{4 E J}{L}+k_{2}\right) x_{4}=0
\end{array}\right.\right.
$$

Solving equations (4.4) to find $x_{2} ; x_{4}$ :

$$
\begin{aligned}
& x_{2}=\frac{\left(4 E J+k_{2} L\right) L k_{1}}{\left(12 E^{2} J^{2}+4 E J k_{2} L+4 k_{1} E J+L^{2} k_{1} k_{2}\right)}, \\
& x_{4}=\frac{-2 E J L k_{1}}{\left(12 E^{2} J^{2}+4 E J k_{2} L+4 L k_{1} E J+L^{2} k_{1} k_{2}\right) L}, \\
& {\left[\begin{array}{llll}
t_{12} & t_{22} & t_{32} & t_{42}
\end{array}\right]^{T}=\left[\begin{array}{llll}
x_{1} & x_{2} & x_{3} & x_{4}
\end{array}\right]^{T} \text {. }}
\end{aligned}
$$

The third column of the matrix $[T]$ is created as boundary conditions, Fig. 1e: 


$$
\begin{aligned}
& \{X\}=\left[\begin{array}{llll}
X_{1} & X_{2} & X_{3} & X_{4}
\end{array}\right]^{T}=\left[\begin{array}{llll}
0 & 0 & 1 & 0
\end{array}\right]^{T}, \\
& f_{2}=-k_{1} x_{2} ; \quad f_{4}=-k_{2} x_{4} ; \quad x_{1}=0, \quad x_{3}=\mathbf{1} .
\end{aligned}
$$

To impose the boundary conditions into equations (4.1) that becomes:

$$
\left\{\begin{array} { l } 
{ \frac { 4 E J } { L } x _ { 2 } - \frac { 6 E J } { L ^ { 2 } } x _ { 3 } + \frac { 2 E J } { L } x _ { 4 } = - k _ { 1 } x _ { 2 } } \\
{ \frac { 2 E J } { L } x _ { 2 } - \frac { 6 E J } { L ^ { 2 } } x _ { 3 } + \frac { 4 E J } { L } x _ { 4 } = - x _ { 4 } k _ { 2 } }
\end{array} \Leftrightarrow \left\{\begin{array}{l}
\left(\frac{4 E J}{L}+k_{1}\right) x_{2}+\frac{2 E J}{L} x_{4}=\frac{6 E J}{L^{2}} \\
\frac{2 E J}{L} x_{2}+\left(\frac{4 E J}{L}+k_{2}\right) x_{4}=\frac{6 E J}{L^{2}}
\end{array}\right.\right.
$$

Solving equations (4.5) to find $x_{2}, x_{4}$ :

$$
\begin{aligned}
& x_{2}=\frac{6 E J\left(2 E J+k_{2} L\right)}{\left(12 E^{2} J^{2}+4 E J k_{2} L+4 L k_{1} E J+L^{2} k_{1} k_{2}\right) L}, \\
& x_{4}=\frac{6 E J\left(2 E J+k_{1} L\right)}{\left(12 E^{2} J^{2}+4 E J k_{2} L+4 L k_{1} E J+L^{2} k_{1} k_{2}\right) L}, \\
& {\left[\begin{array}{llll}
t_{13} & t_{23} & t_{33} & t_{43}
\end{array}\right]^{T}=\left[\begin{array}{llll}
x_{1} & x_{2} & x_{3} & x_{4}
\end{array}\right]^{T} \text {. }}
\end{aligned}
$$

The fourth column of the matrix $[T]$ is created as boundary conditions, Fig. 1f:

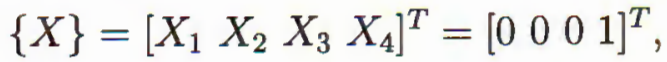

$$
\begin{aligned}
& f_{2}=-k_{1} x_{2} ; \quad f_{4}=k_{2}-k_{2} x_{4} ; \quad x_{1}=0, \quad x_{3}=0 .
\end{aligned}
$$

To impose the boundary conditions into equations (4.1) that becomes:

$$
\left\{\begin{array} { l } 
{ \frac { 4 E J } { L } x _ { 2 } + \frac { 2 E J } { L } x _ { 4 } = - k _ { 1 } x _ { 2 } } \\
{ \frac { 2 E J } { L } x _ { 2 } + \frac { 4 E J } { L } x _ { 4 } = k _ { 2 } - k _ { 2 } x _ { 4 } }
\end{array} \Leftrightarrow \left\{\begin{array}{l}
\left(\frac{4 E J}{L}+k_{1}\right) x_{2}+\frac{2 E J}{L} x_{4}=0 \\
\frac{2 E J}{L} x_{2}+\left(\frac{4 E J}{L}+k_{2}\right) x_{4}=k_{2}
\end{array}\right.\right.
$$

Solving equations (4.6) to find $x_{2}, x_{4}$ :

$$
\begin{aligned}
& x_{2}=\frac{-2 E J L k_{2}}{\left(12 E^{2} J^{2}+45 E J k_{2} L+4 L k_{1} E J+L^{2} k_{1} k_{2}\right)}, \\
& x_{4}=\frac{\left(4 E J+k_{1} L\right) L k_{2}}{\left(12 E^{2} J^{2}+4 E J k_{2} L+4 L k_{1} E J+L^{2} k_{1} k_{2}\right)}, \\
& {\left[\begin{array}{llll}
t_{14} & t_{24} & t_{34} & t_{44}
\end{array}\right]^{T}=\left[\begin{array}{llll}
x_{1} & x_{2} & x_{3} & x_{4}
\end{array}\right]^{T} \text {. }}
\end{aligned}
$$

From Fig. 2b we have the transformation matrix as follows

$$
[e]=\left[\begin{array}{cccc}
1 & e_{1} & 0 & 0 \\
0 & 1 & 0 & 0 \\
0 & 0 & 1 & -e_{2} \\
0 & 0 & 0 & 1
\end{array}\right]
$$


5. Second order elastic analysis of steel frames with semi-rigid connections and rigid zones

The linear elastic analysis assumes that the deformations are relatively small, and the equilibrium equations can be formulated with respect to initial geometry. When increasing applied loads which cause significant changes in the structure's geometry, the equilibrium and compatibility equations are nonlinear and the resulting stiffness matrix contains terms that are functions of axial forces and deformations. The stiffness matrix representing this behavior must include the effect of geometry nonlinearity. In addition, for members with flexible connections and rigid-zones at the ends, the stiffness matrix and geometric stiffness matrix must be modified taking into account the effect of connection flexibility and rigid-zones. The structural stiffness equations formed by superimposing the member stiffnesses include effects of geometric nonlinearity and connection flexibility and rigid-zones.

The equilibrium equations are written in terms of the geometry of the deformed structure:

$$
\left(\left[K^{*}\right]+\left[K_{\sigma}^{*}\right]\right)\left\{X^{*}\right\}=\left\{F^{*}\right\},
$$

where $\left[K_{\sigma}^{*}\right]$ represents the change in stiffness that results from the deformations of the system (the geometric nonlinearity). The normal procedure is to solve the problem in a series of linear steps, in each of which $\left[K_{\sigma}^{*}\right]$ can be written as a function of forces and deformations known at the start of the step and the total global stiffness matrix $\left(\left[K^{*}\right]+\left[K_{\sigma}^{*}\right]\right)$ treated as a tangent stiffness matrix, $\left[K_{t}\right]$. Hence $\left\{X^{*}\right\}$ and $\left\{F^{*}\right\}$ assume the incremental form of Eqn (5.1). A second order elastic analysis (or P-Delta effect) can produce an excellent representation of de-stabilizing influences and it has provisions for detecting critical loads.

\section{Numerical examples for verification}

These are three two-dimensional frames in [2], [3], [4], as shown in figures 3, 4, 5 . The purpose of these examples is to verify the adequacy of the P-Delta algorithm in Program written by Pascal language for these types of problems. Theoretical results for these problems can be derived using the stability function approach. Tables for stability functions can be obtained from References [4]. The agreement between the numerical and theoretical results is excellent. The values in columns (2) and (9) are respectively $P_{c r}$ (P-critical) of frames with pin and fixed beam column connections. The values in columns (3) to $(8)$ are $P_{c r}$ of frames with semi-rigid connections between beam and column. Rotational springs can be used to model semi-rigid restraint conditions. The restraint conditions can be characterized by a quantity called the joint stiffness $\alpha=\frac{k}{i_{x}}$, where $i_{x}$ - the flexural stiffness of the beam. 


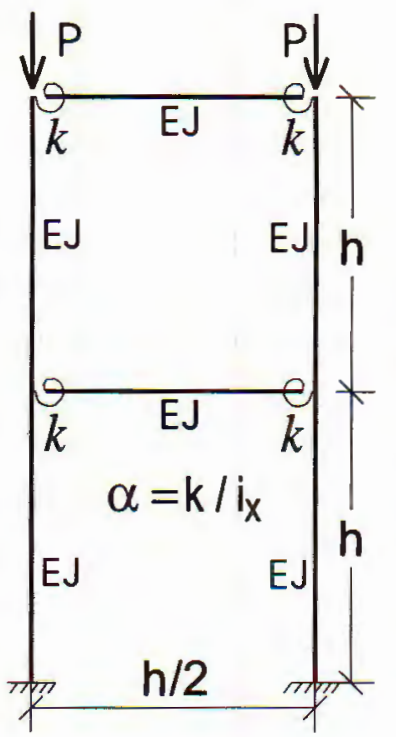

Fig. 3

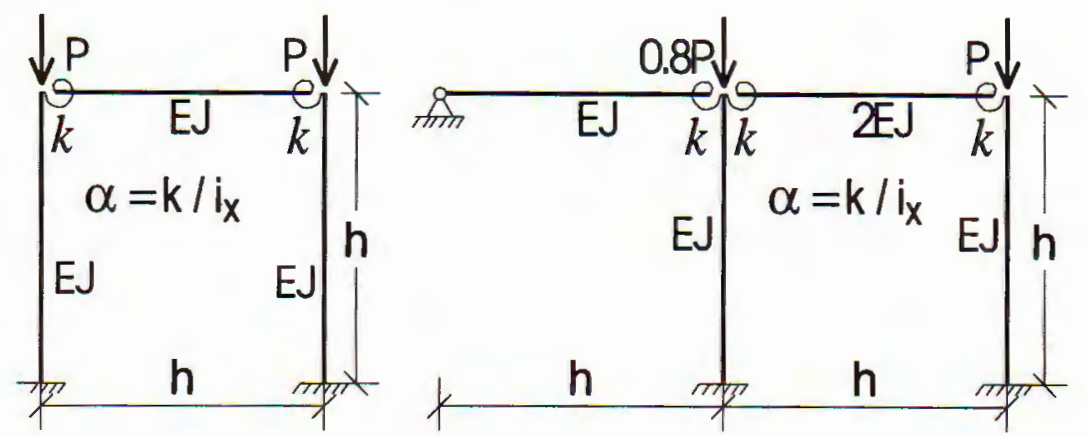

Fig. 4

Fig. 5

Table 1. $P_{c r}$ for frames with semirigid connection

\begin{tabular}{|c|c|c|c|c|c|c|c|c|}
\hline \multirow{2}{*}{ Fig } & \multirow{2}{*}{$\begin{array}{c}\text { Pin } \\
\text { Con- } \\
\text { nection }\end{array}$} & \multicolumn{6}{|c|}{ Semi-rigid connections $\alpha=k / i_{x}$} & \multirow{2}{*}{$\begin{array}{l}\text { Fixed } \\
\text { Con- } \\
\text { nection }\end{array}$} \\
\hline & & 0.001 & 0.01 & 0.1 & 1 & 10 & 100 & \\
\hline 1 & 2 & 3 & 4 & 5 & 6 & 7 & 8 & 9 \\
\hline III & 0.617 & 0.620 & 0.632 & 0.761 & 1.181 & 4.952 & 6.548 & 6.760 \\
\hline IV & 2.485 & 2.487 & 2.507 & 2.681 & 3.954 & 6.5 & 7.339 & 7.344 \\
\hline $\mathrm{V}$ & 20.707 & 20.715 & 20.738 & 21.020 & 23.184 & 28.785 & 31.020 & 30.90 \\
\hline
\end{tabular}

\section{Conclusions}

The present study aims at developing a computer-oriented stability analysis by using P-Delta effect for steel framed structures with semirigid connections and rigid zones. A second-order nonlinear approach is adopted to include both geometric nonlinearity and connection flexibility.

The stiffness matrix and geometric stiffness matrix of beam element with semirigid connections and rigid zones are derived by using transformation matrices $[T]$ and $[e]$. The derived matrices not only include the effects of axial force (tension or compression) on the flexural stiffnesses but also effects of (1) flexural deformations on the axial stiffness; and (2) flexural semi-rigid connections and rigid zones at the beam's ends. Both matrices are necessary in the stability and second-order elastic analyses of frames with semi-rigid connections and rigid-zones. The derived matrices are limited to the elastic stability and second order analyses of framed structures. 
For determining properly the buckling strength of individual members in steel framed structures with semi-rigid connections and rigid-zones, the analysis should be focused on the in-plane stability of the overall structural system rather than on the in-plane stability of individual members. In this paper, the framework structure will be taken as the whole for determination of the critical load. For this reason, the designer should conduct a full stability analysis for the given structure under a specific design loading to determine the proper buckling strength of structure. This study provides an approach to obtain more accurate estimation of the stability behavior and better to determine the capacities of the structure.

A Pascal code has been written for the stability analysis by using P-Delta effect in this study based on above derivations for conducting system buckling analysis. The validity of the program is substantiated by the test cases.

\section{REFERENCES}

1. CookR. D., Malkus D. S. and PleshaM. E. "Concepts and Applications of Finite Element Analysis", Third Edition, John Wiley and Sons, Inc, ISBN 0-471-847887,1989

2. Column Research Committee of Japan. "Handbook of Structural Stability", Corona Publishing Company, LTD Tokyo -Japan 1971.

3. George J. Simitses. "An Introduction to the Elastic Stability of Structures", Prentice-Hall, INC., Englewood Cliffs, New jersey - USA 1976.

4. Phạm Khắc Hùng, Đào Trọng Long, Lê Văn Quý, Lều Thọ Trình. "Dynamic and Stability of Structure", Education Publisher, Hà Nội 1974, (In Vietnamese).

5. Reddy J. N. "An Introduction to the Finite Element Method", Second Edition, McGraw-Hill, Inc. New York 1993.

Received September 27, 2001

PHÂN TÍCH ỔN ĐỊNH CỦA KẾT CÂU KHUNG THÉP CÓ NÚT CƯNG VÀ LIÊN KẾT MỀM BẰNG CÁCH SƯ DƯNG HIỆU ỨNG P-DELTA

Phân tích nội lực có xét đến "' hiệu ứng P-Delta", với thành phần lực dọc và chuyển vị đủ lớn kết cấu có thể mất ổn định, do đó cần sử dụng "hiệu ứng P-Delta" để phân tích ổn định của hệ kết cấu. Mục đích của bài báo là sư dụng phương pháp phần tử hữu hạn thiết lập bài toán phân tích ổn định của kết cấu khung thép có nút cứng và liên kết mềm bằng cách sử dụng "hiệu ứng P-Delta". 